\title{
Pollutants-Focus on Solving Environmental Pollution Problems
}

\author{
Ali Elkamel
}

check for updates

Citation: Elkamel, A.

Pollutants-Focus on Solving

Environmental Pollution Problems.

Pollutants 2021, 1, 65.

https://doi.org/10.3390/

pollutants1010006

Received: 26 January 2021

Accepted: 2 March 2021

Published: 8 March 2021

Publisher's Note: MDPI stays neutral with regard to jurisdictional claims in published maps and institutional affiliations.

Copyright: (C) 2021 by the author. Licensee MDPI, Basel, Switzerland. This article is an open access article distributed under the terms and conditions of the Creative Commons Attribution (CC BY) license (https:// creativecommons.org/licenses/by/ $4.0 /)$.
Department of Chemical Engineering, University of Waterloo, 200 University Avenue West, Waterloo, ON N2L 3G1, Canada; aelkamel@uwaterloo.ca; Tel.: +1-519-888-4567

Pollutants (ISSN 2673-4672) is an international, peer-reviewed open access journal focusing on contaminants that are introduced into the natural environment, beyond permitted limits, and cause measurable deleterious effects on air, water, soil, or living organisms. It is a new comprehensive journal on the subject of pollution covering a broad spectrum of topics relevant to environmental health sciences and public health protection. Pollutants includes, but is not limited to toxicology, water resources, geosciences, atmospheric chemistry, environmental microbiology/bio-based energy sources, ecosystem restoration, environmental analyses and monitoring, assessment of risks and interactions of pollutants in the environment, conservation biology and sustainable agriculture, impact of pollutants on human and animal health and other emerging fields.

The scope of Pollutants mainly includes three type of pollutants: chemical pollutants, biological pollutants and physical pollutants. The chemical pollutants are the result of various human activities including both organic and inorganic contaminants such as plastics, heavy metals, insecticides, herbicides and combustion products of fossil fuels. The biological pollutants are substances in our environment which come from living organisms. For example, pollens, dust mites, mold and fungi. There are also physical pollutants characterized by their influence on the environment and its inhabitants caused by forces and operations of physics including light, noise and radiation (electric radiation/magnetic radiation/nuclear radiation).

This international journal is holistic in nature and covers high quality research on pollutants, contaminated natural resources, the interactions between them and related aspects such as pollutants monitoring, pollutants removal, pollutants prevention and control. Particular attention will be paid to the advanced monitoring equipment and novel technologies for purification or degradation.

Accordingly, high quality research works falling within the mentioned scopes are welcomed. We encourage scientists to submit their high quality research works related to chemical, biological and physical compounds that lead to pollution, including impact assessment studies and corresponding remediation strategies to promote the scientific utilization and effective mitigation of pollutants.

Acknowledgments: The editor is grateful to all the authors who contributed their work and to the expert peer reviewers that contribute with their rigorous evaluations of all the manuscripts submitted to this Special Issue. The valuable contribution, organization, and editorial support of the MDPI management team and staff is greatly acknowledged.

Conflicts of Interest: The author declares no conflict of interest. 